\title{
A Review on Abrasive Waterjet and Wire Electrical Discharge Machining - High Speed
}

\author{
Shijin Zhang, Yuqiang Wu and Yanli Wang
}

\author{
College of Resources and Environmental Science, State and Local Joint Engineering Laboratory of Methane Drainage \\ in Complex Coal Gas Seam, Key Laboratory for the Exploitation of Southwest Resources and Environmental Hazards \\ Control Engineering of Ministry of Education, Chongqing University, Chongqing, 400030, P.R. China
}

\begin{abstract}
Technological advancement, on the one hand, makes Electrical Discharge Machining (EDM) much faster. One example of that is the presence of Wire Electrical Discharge Machining - High Speed (WEDM-HS) machine, which makes the material removal rate as high as $80 \mathrm{~mm}^{2} / \mathrm{min}$. On the other hand, it also make Abrasive Waterjet (AWJ) achieve much better quality surface and tighter tolerance. As a result, these two machining processes have converged to the point where they can achieve same requirements quite nicely in selected applications. However, when examining closely, these two processes are quite different in many aspects. This paper reviews the main features of these two processes. The review leads to the essential differences between these two processes. Based on this review, proper applications of each process has been provided.
\end{abstract}

Keywords: WEDM-HS, AWJ, cutting mechanism, cutting quality, surface damage, cutting efficiency.

\section{INTRODUCTION}

As is well-known, Wire Electrical Discharge Machining (WEDM) is a metalworking process in which material is removed by an electrical charged wire from a conductive workpiece. In this process, a very thin wire, made from brass or molybdenum, and served as an electrode (called toolelectrode), is slowly fed through the material which is served as another electrode (called workpiece-electrode). Material is then removed from the workpiece by a series of rapidly recurring current discharges between these two electrodes, which are separated by a dielectric liquid and subject to an electric voltage [1]. Because WEDM removes metal by producing a rapid series of repetitive electrical discharges, WEDM is sometimes also called "spark machining".

The popularity of this non-traditional machining process is owing to its special advantages, which include, (1). Machining of complex shapes which is otherwise too difficult to be produced with conventional cutting tools; (2). Machining of extremely hard material with high precision; (3). Machining of very small workpieces where conventional cutting tools may damage the part from excess cutting force; (4). There is no direct contact between tool and workpiece. Therefore, delicate sections and weak materials can be machined without any distortion by using WEDM [1]. Because of the above advantages, WEDM has been used extensively in tool and die industry for mold-making [2]. However, WEDM process is also regarded as a very slow material removal process, which limits its further applications greatly.

\footnotetext{
*Address correspondence to this author at the College of Resources and Environmental Science, Chongqing University, Chongqing, 400030, P.R. China; Tel: +86-023-65106122(office), $+86-13648438470$ (Mobile); Fax: +86-023-65106122;

E-mail: zhangshij@hotmail.com, shijinzhang@cqu.edu.cn
}

Traditionally, WEDM is used to solve the processing problems of materials with special mechanical properties, such as high melting point, high hardness and ductility, and the parts will be with special structure and requirements, which are difficult or unsolvable for the traditional process [3]. Wire Electrical Discharge Machining - High Speed (WEDM-HS), just as its name implies, is a high speed wire electrical discharge machining process. In WEDM-HS process, molybdenum wire moves back and forth in a relatively high speed which is as high as 10 meters/s $[4,5]$. The high-speed-moving molybdenum wire, on the one hand, makes the material removal rate much higher, which improves cutting efficiency greatly. On the other hand, however, it also makes the cutting surface much rougher because of the vibration of the wire. As a result, high cutting efficiency and rough surface is expected when cutting with WEDM-HS. For many applications in which cutting efficiency is more important than precision, WEDM-HS is a better choice than WEDM. Currently, WEDM-HS has been used extensively in tool and die industry. Statistical data shows that, till 2009, around 50,000 WEDM machines have been used in industry in China, and $95 \%$ of them are WEDM-HS machines [6]. This implies the potential of this technology.

Abrasive Waterjet (AWJ) is also a material working process in which material is separated by a very thin high speed abrasive water jet beam. In a typical AWJ cutting process, water is pressurized to a very high pressure (up to $600 \mathrm{MPa}$ ) by a pump [7] and forced through a very small orifice $(0.1 \mathrm{~mm} \sim 0.5 \mathrm{~mm})$. After it comes out, a high velocity water jet beam is formed. This high velocity water jet beam can be used to cut soft materials such as rock, plastic and wood, etc.. When abrasive particles are added into this high velocity water jet beam, its cutting power is increased dramatically. In this case, water is no longer the cutting medium but the accelerating medium that transfers its 
momentum to abrasive particles which are entrained into a so-called mixing chamber from a hopper, as shown in Fig. (1). This high energy abrasive stream can cut through almost all kinds of materials, including diamonds.

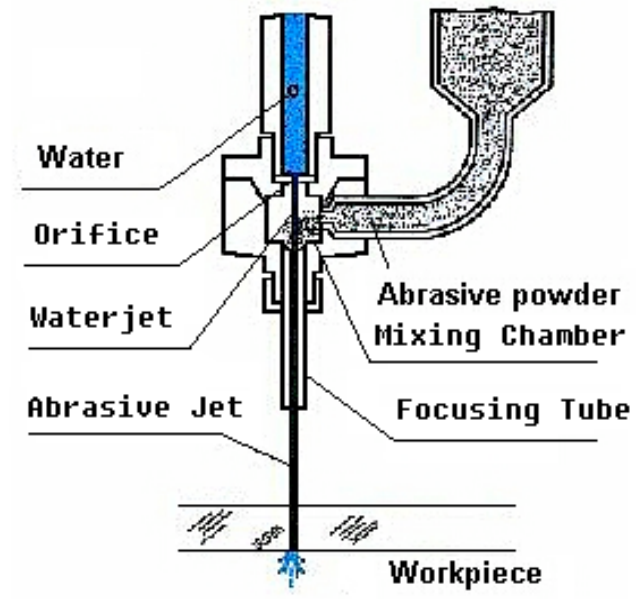

Fig. (1). Typical abrasive water-jet cutting head.

Traditionally, AWJ is regarded as a rough cutting method which is only used for difficult-to-cut material. The reason is that, AWJ is a 'beam' cutting technology which is characterized by its energy dissipation phenomenon. In AWJ cutting process, when the jet beam impacts on target material, the beam and abrasive particles might bounce back and forth in the cutting zone, and secondary, tertiary impacts of the deflected jet would be expected [8]. These secondary and tertiary impacts of the deflected jet may cause striation marks on the cutting surface. These striation marks make most surfaces too rough to be accepted. These striation marks limit AWJ's applications greatly.

The technological advancements, on the one hand, make modern EDM much faster, on the other hand, allow AWJ to hold much tighter tolerance and produce better edges [9]. As early as 2001, researchers from Japan had increased machining speed by approximately $40 \%$ only by developing highspeed electrod wire $[10,11]$. In 2009, Wang et al. worked on multi-axis HS-WEDM system to improve productivity [12]. In the same year, Wang et al. also used dry WEDM to improve HS-WEDM surface roughness [13]. Now, $40 \mathrm{~mm}^{2} / \mathrm{min}$ cutting speed and $2.5 \mathrm{~mm}^{2} / \mathrm{min}$ it materials are then flushed away by a continuously flowing fluid. During this process, a lot of heat is expected to be generated in the cutting zone, though the heat should be only concentrated in a very small area for each electrical discharge. As a process with high efficiency, more heat is expected to be generated during WEDM-HS cutting process.

Different from WEDM-HS, in AWJ metal working process, material is separated by a very thin high speed abrasive water jet beam. In this process, each abrasive particle acts as a micro-knife which cut away a small amount of material. Although micro-cutting would generate some heat, the heat is limited in a small local area and it would be taken away by high speed jet beam quickly. Therefore, AWJ is regarded as a cold-working process in which only a small amount of heat is expected.
In order to further demonstrate the working mechanism of both WEDM-HS and AWJ, a 99.4\% pure aluminum plate and $1 \mathrm{Cr} 18 \mathrm{Ni}$ Ti stainless steel plate have been cut by WEDM-HS and AWJ respectively and the cutting surfaces have been investigated. Both aluminum and stainless steel plate cutting have been carried out on a DK7725 WEDM-HS machine and OMAX2626/XP AWJ machining center respectively with proper cutting parameters.
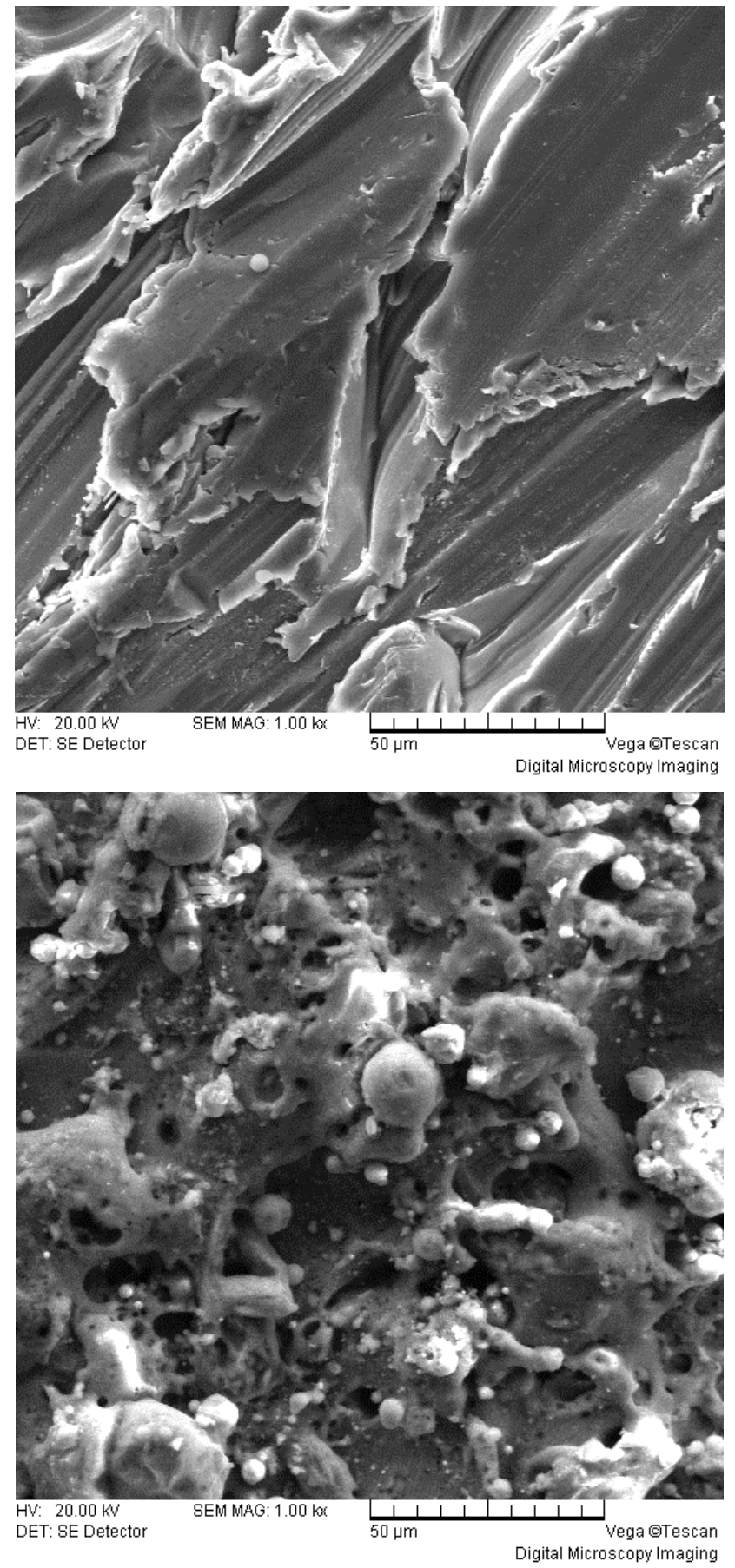

Fig. (2). Microstructure of aluminum surface cut by WEDM-HS and AWJ respectively at 1000 times magnification (surface cut by AWJ on left side and surface cut by WEDM-HS on right side).

As shown in Figs. (2 and 3), ball-shaped materials with different sizes and cavities distributed evenly on aluminum surface cut by WEDM-HS. These ball-shaped materials with 
very smooth outside surface imply that melting occurs during material separating process. On surfaces cut by AWJ,
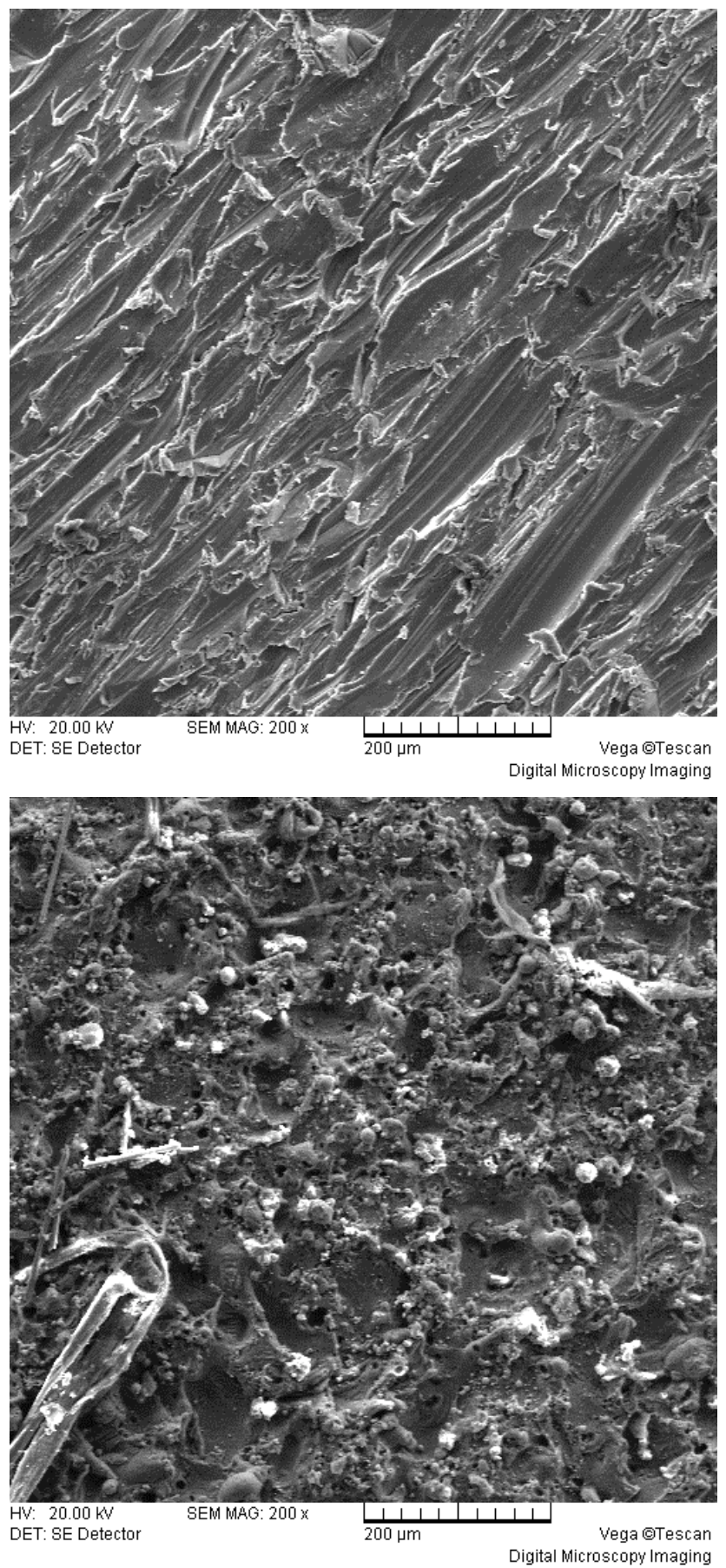

Fig. (3). Microstructure of aluminum surface cut by WEDM-HS and AWJ respectively at 200 times magnification (surface cut by AWJ on left side and surface cut by WEDM-HS on right side).

instead of ball-shaped materials and cavities, short small grooves distributed all over the cutting surface. Those small grooves are caused by micro-cutting of abrasive particles obviously which demonstrates that each abrasive particle acts as a micro-knife and cuts a small amount of material away. Figs. (4 and 5) show similar trends in which small size ball-shape materials with smooth outside surfaces presented on stainless steel surface cut by WEDM-HS and microcutting grooves presented on surfaces cut by AWJ. Based on the above analysis, in WEDM-HS machining process, micromelting is the major machining mechanism. However, in AWJ machining process, micro-cutting instead of micromelting is the major machining mechanism for ductile material. On surface cut by AWJ, no matter whether the material is aluminum or stainless steel, there is no any sign which implies melting occurred. This demonstrates that AWJ is a cold working process.
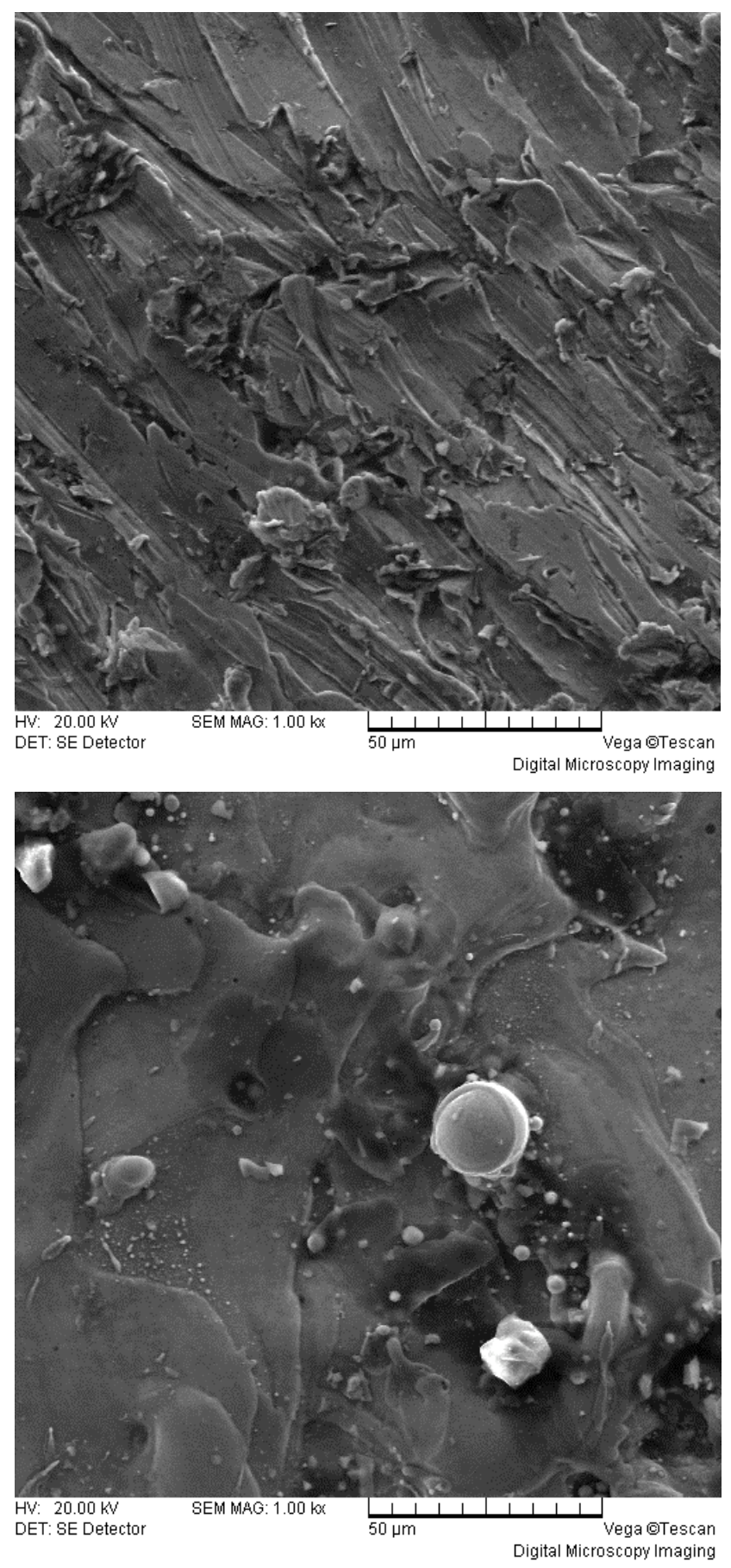

Fig. (4). Microstructure of stainless steel surface cut by WEDM-HS and AWJ respectively at 1000 times magnification (surface cut by AWJ on left side and surface cut by WEDM-HS on right side). 

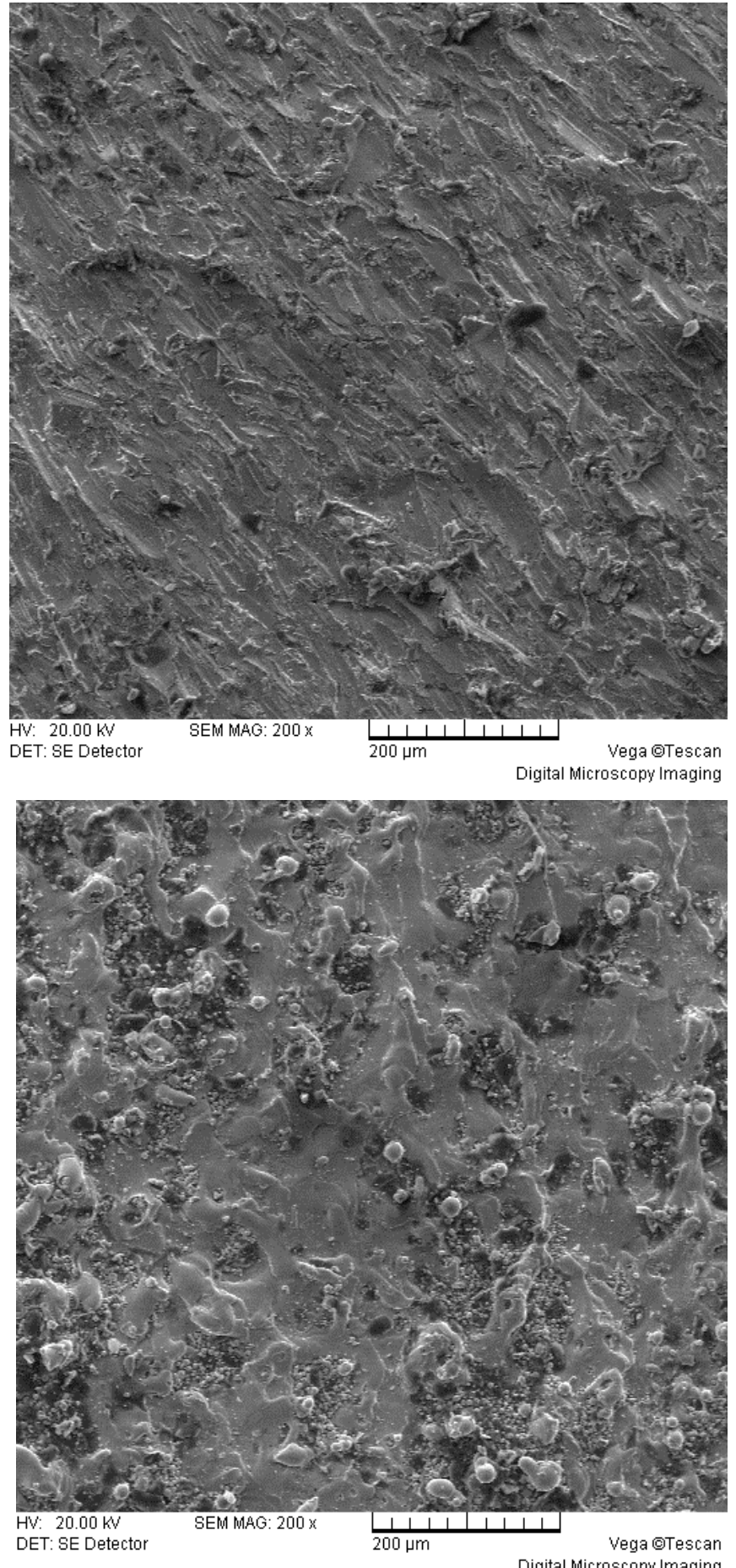

Fig. (5). Microstructure of stainless steel surface cut by wire EDMHS and AWJ respectively at 200 times magnification (surface cut by AWJ on left side and surface cut by WEDM-HS on right side).

\section{CUTTING QUALITY COMPARISONS BETWEEN WEDM-HS AND AWJ}

High cutting quality, which includes cutting precision and surface roughness, is one of the most important reasons for WEDM to be used extensively. For WEDM, as high as $\pm 0.005 \mathrm{~mm}$ tolerance has been reported [14]. As mentioned above, WEDM-HS has the characteristics of high efficiency but low accuracy, even then, $\pm 0.02 \mathrm{~mm}$ has been achieved for the dimension precision [15].

Though regarded as a rough cutting process for a long time, AWJ has been improved greatly in cutting precision and accuracy in the last 10 years. Currently, for a typical cutting, as high as $\pm 0.025 \mathrm{~mm}$ locating tolerance has been achieved by using OMAX cutting system [16-18], which is very close to the dimension precision achieved by WEDMHS.

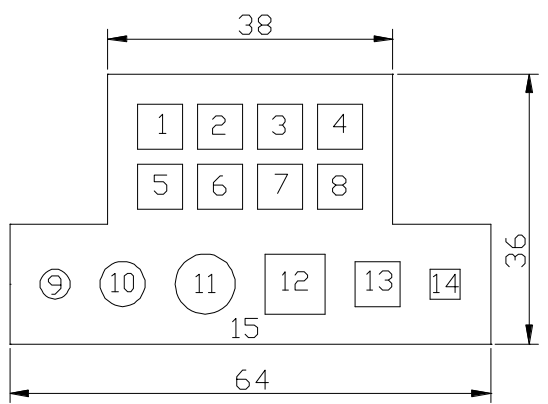

Fig. (6). Specially designed sample with 15 features itemed as 1 to 15 (unit in $\mathrm{mm}$ ).

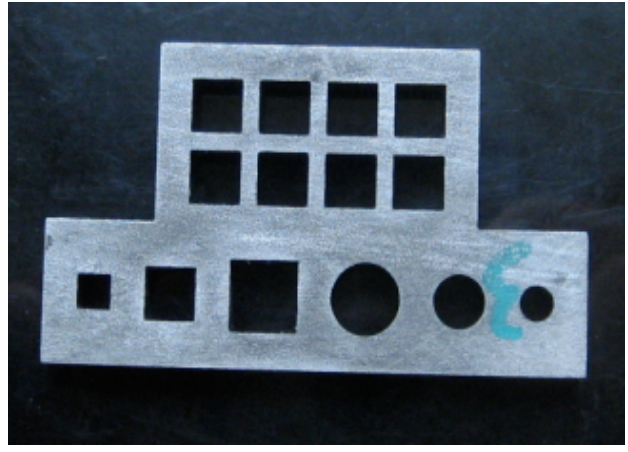

Fig. (7). Sample cut by WEDM-HS.

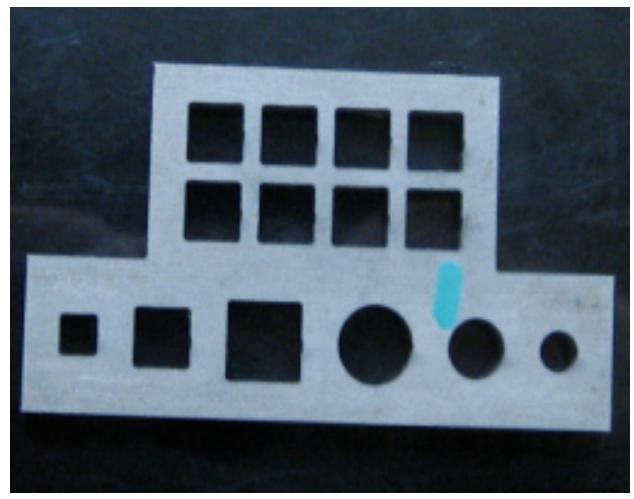

Fig. (8). Sample cut by AWJ.

In order to compare the dimension precision achieved by WEDM-HS and AWJ, a stainless steel sample with different size holes and square features on has been specially designed and machined, as shown in Figs. $(6,7,8$ and 9). Cutting parameters used in both WEDM-HS and AWJ have been listed in Table $\mathbf{1}$ and $\mathbf{2}$. 
Table 1. WEDM-HS Cutting Parameters for Sample

\begin{tabular}{|c|c|}
\hline Machine model & DK7725 WEDM-HS \\
\hline \hline Wire type & molybdenum \\
\hline Wire diameter & $0.18 \mathrm{~mm}$ \\
\hline Cutting speed & $50 \mathrm{~mm}^{2} / \mathrm{min}$ \\
\hline Operating current & $2.5 \mathrm{~A}$ \\
\hline Consumed electrical power & $1.5 \mathrm{KVA}$ \\
\hline Target material & $1 \mathrm{Cr} 18 \mathrm{Ni9Ti}$ stainless steel \\
\hline Target material thickness & $6 \mathrm{~mm}$ \\
\hline
\end{tabular}

Table 2. AWJ Cutting Parameters for Sample

\begin{tabular}{|c|c|}
\hline Machine model & OMAX2626/XP with a tilt-a-jet \\
\hline \hline Water pressure & $350 \mathrm{MPa}$ \\
\hline Orifice diameter & $0.35 \mathrm{~mm}$ \\
\hline Mixing tube diameter & $0.76 \mathrm{~mm}$ \\
\hline Abrasive flowrate & $0.367 \mathrm{~kg} / \mathrm{min}$ \\
\hline Abrasive mesh size & 100 mesh \\
\hline Cutting quality & quality 3 and 5 respectively \\
\hline Cutting speed & calculated by OMAX software \\
\hline Target material & 1Cr18Ni9Ti stainless steel \\
\hline Target material thickness & $6 \mathrm{~mm}$ \\
\hline
\end{tabular}

For convenient reason, holes and square features have been itemed as 1 to 15, as shown in Fig. (6). To simplify the table, only items 9 to 15 , which include different sizes hole, square feature and outline profile, have been picked and their dimensions have been listed. For each feature, only the diameter for each hole, the length for each square feature and outline profile have been listed as shown in Table $\mathbf{3}$.

As shown in Table $\mathbf{3}$, in actual cutting, similar accuracy has been achieved by WEDM-HS and AWJ. However, for all samples, the accuracy of several dimensions is beyond $\pm 0.1 \mathrm{~mm}$ which is too far away from what these two machines would achieve. Adjustment is definitely needed to obtain tighter tolerances. Need to note that, taper, a typical feature on AWJ cutting surface, have been removed completely by using tilt-a-jet apparatus on OMAX 2626/XP machining center.

Except dimension precision, surface roughness is another very important reason for WEDM to be used extensively. As mentioned above, very smooth surface is expected during WEDM machining process. However, for WEDM-HS, rough surface should be expected because of high cutting speed. In order to find out whether both WEDM-HS and AWJ can achieve the same surface quality, four samples have been cut, two cut by WEDM-HS and another two cut by AWJ. Cutting parameters are listed in Table $\mathbf{1}$ and $\mathbf{2}$. And the cutting surface roughness has been investigated for each sample. The instrument used for surface roughness measurement is TR200 Roughness Tester, and the Cutoff distance is $0.8 \mathrm{~mm}$. The measurement results have been listed in Table 4. What needs to be pointed out is that, for samples cut by AWJ, striation marks are expected on lower side of the cutting surface. In another word, the upper side surface is expected to be smoother than the lower side surface. In practice, rougher side is the one which decides the surface quality. Therefore, lower side surface has been picked for surface roughness measurement. Theoretically, measurement area should be very close to the bottom line of the cutting surface since that area is the roughest area, however, in practice, it is very difficult to do that. So, the area which is about $2 \mathrm{~mm}$ away from the bottom line of each sample has been used for surface roughness measurement. And for each sample, the top surface, as shown in Fig. (9), has been selected as the measurement surface.

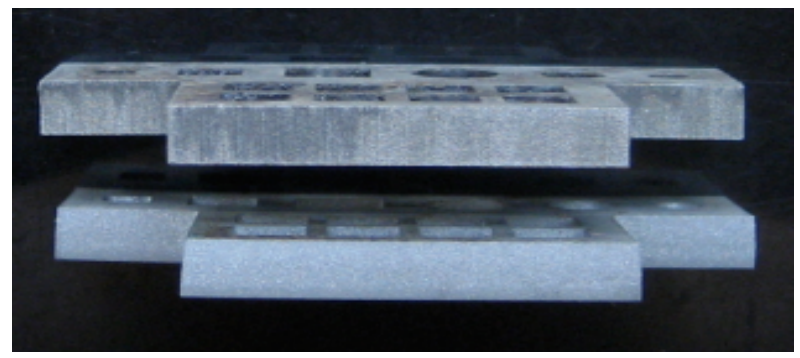

Fig. (9). Surface profile comparison cut by wire EDM-HS and AWJ respectively (sample cut by wire EDM-HS on upper side, sample cut by AWJ on lower side).

As shown in Table 4, smoother surfaces have been achieved when using AWJ, no matter whether quality 3 or quality 5 is used. Theoretically, surface cut with quality 5 should be smoother than surface cut with quality 3 . However, in this test, not much difference has been

Table 3. Dimension Precision Comparison for each Picked Feature Cut by Wire EDM-HS and AWJ respectively

\begin{tabular}{|c|c|c|c|c|c|c|}
\hline Feature & I 9 & I 10 & I 11 & I 12 (length) & I 13 (length) & I 14 (length) \\
\hline \hline Machining Methods & $\varphi 4$ & $\varphi 6$ & $\varphi 8$ & 4 & 6 & 8 \\
\hline Ideal Dimension (mm) & 4.06 & 6.14 & 7.94 & 4.14 & 6.14 & 8.24 \\
\hline Wire EDM-HS (mm) & 4.18 & 6.04 & 8.06 & 4.11 & 6.14 & 8.23 \\
\hline AWJ (quality 5 sample) (mm) & 4.16 & 6.11 & 8.02 & 4.11 & 6.12 & 8.14 \\
\hline AWJ (quality 3 sample) (mm)
\end{tabular}


Table 4. Surface Roughness Comparison Cut by WEDM-HS and AWJ

\begin{tabular}{|c|c|c|c|c|}
\hline $\begin{array}{l}\text { Roughness } \\
\text { (um) }\end{array}$ & $\begin{array}{c}\text { Samples \#1 (AWJ quality } \\
\mathbf{5}\end{array}$ & $\begin{array}{c}\text { Sample \#2 (AWJ quality } \\
\text { 3) }\end{array}$ & Sample \#3 (WEDM-HS) & Sample \#4 (WEDM-HS) \\
\hline \hline $\mathrm{Ra}$ & 3.020 & 3.186 & 5.016 & 4.510 \\
\hline $\mathrm{Rq}$ & 3.891 & 3.845 & 6.060 & 5.727 \\
\hline $\mathrm{Rz}$ & 19.45 & 18.21 & 24.79 & 25.24 \\
\hline
\end{tabular}

observed. The main reasons might be that, the sample is not very thick, and it is very hard to control the measurement area accurately.

\section{SURFACE DAMAGE COMPARISONS BETWEEN WEDM-HS AND AWJ}

As mentioned above, WEDM-HS is a micro-melting process in which high temperature is expected locally. But for AWJ, though some heat might be generated during micro-cutting process, the heat is taken away quickly by high speed water jet beam. Therefore, AWJ is a cold working process. Theoretically, for any cutting process, if a lot of heat is generated in cutting zone, a recast layer, no matter thin or thick, is expected to be generated. Usually, recast layer is the zone in which micro-cracks start to initialize. Therefore, most of time, it's a good idea to avoid the generation of recast layer. As a micro-melting process, much heat is expected in WEDM cutting zone, especially for WEDM-HS in which higher cutting speed is expected. Further study needs to be done on investigating the recast layer on surface cut by WEDM-HS. But for AWJ, since it is a cold working process, much less heat is expected. From this point of view, less damage has been generated when cut by AWJ.

Another characteristic shared by both WEDM-HS and AWJ is that, very low cutting force has been added on target material. Therefore, almost no deformation is expected on surfaces cut by these two machining processes. In order to verify the above assumption, a closed-cell aluminum foam plate $(6 \mathrm{~mm}$ thick), as shown in Fig. (10), has been cut by

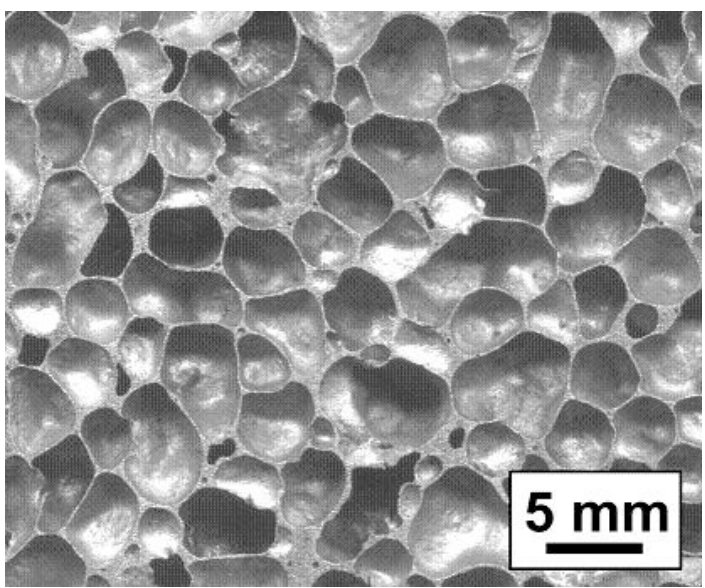

Fig. (10). Closed-cell aluminum foam cut by WEDM-HS and AWJ.
WEDM-HS and AWJ respectively. As is well known, closed-cell aluminum is a cellular structure consisting of a solid aluminum which contains a large volume fraction of gas-filled pores. This structure is usually with very light weight (typically $10 \sim 25 \%$ of the density of aluminum) and very thin weak wall between cells. Because of this, even very small cutting force would smash the wall quickly.
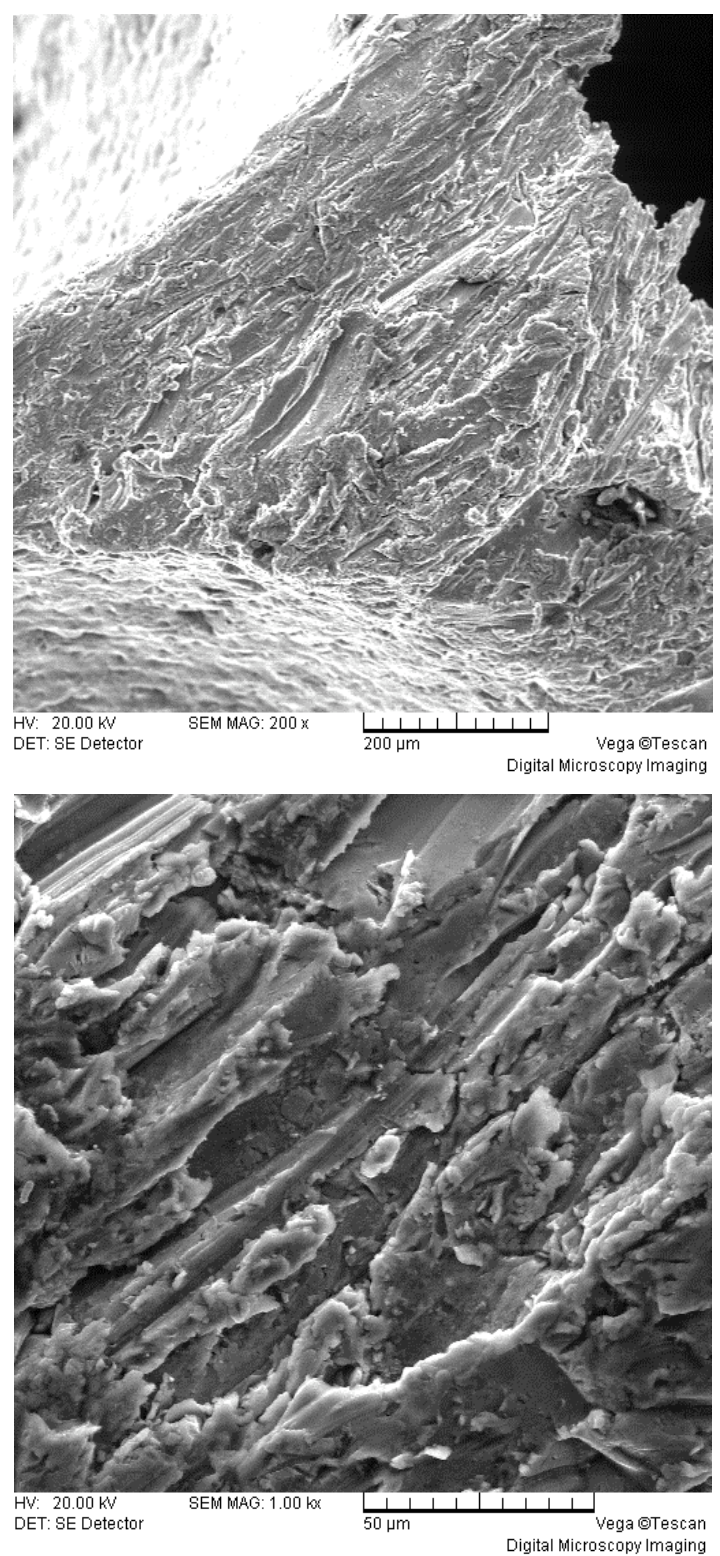

Fig. (11). Microstructure of closed-cell aluminum foam cut by AWJ (48ksi-q5-0.014-0.030nozzle) 
Table 5. Time Consumed for each Wire EDM-HS Sample Feature

\begin{tabular}{|c|c|c|c|c|c|c|c|c|c|c|c|c|c|c|c|c|}
\hline \multirow{2}{*}{ Machining feature } & I & $\mathrm{I}$ & I & I & I & I & I & I & I & I & I & I & I & I & I & \multirow{2}{*}{ Total } \\
\hline & 1 & 2 & 3 & 4 & 5 & 6 & 7 & 8 & 9 & 10 & 11 & 12 & 13 & 14 & 15 & \\
\hline Consumed time $(\mathrm{min})$ & 10 & 10 & 10 & 10 & 10 & 10 & 10 & 10 & 8.5 & 9.3 & 10 & 10.8 & 10 & 9 & 24 & 161.6 \\
\hline
\end{tabular}
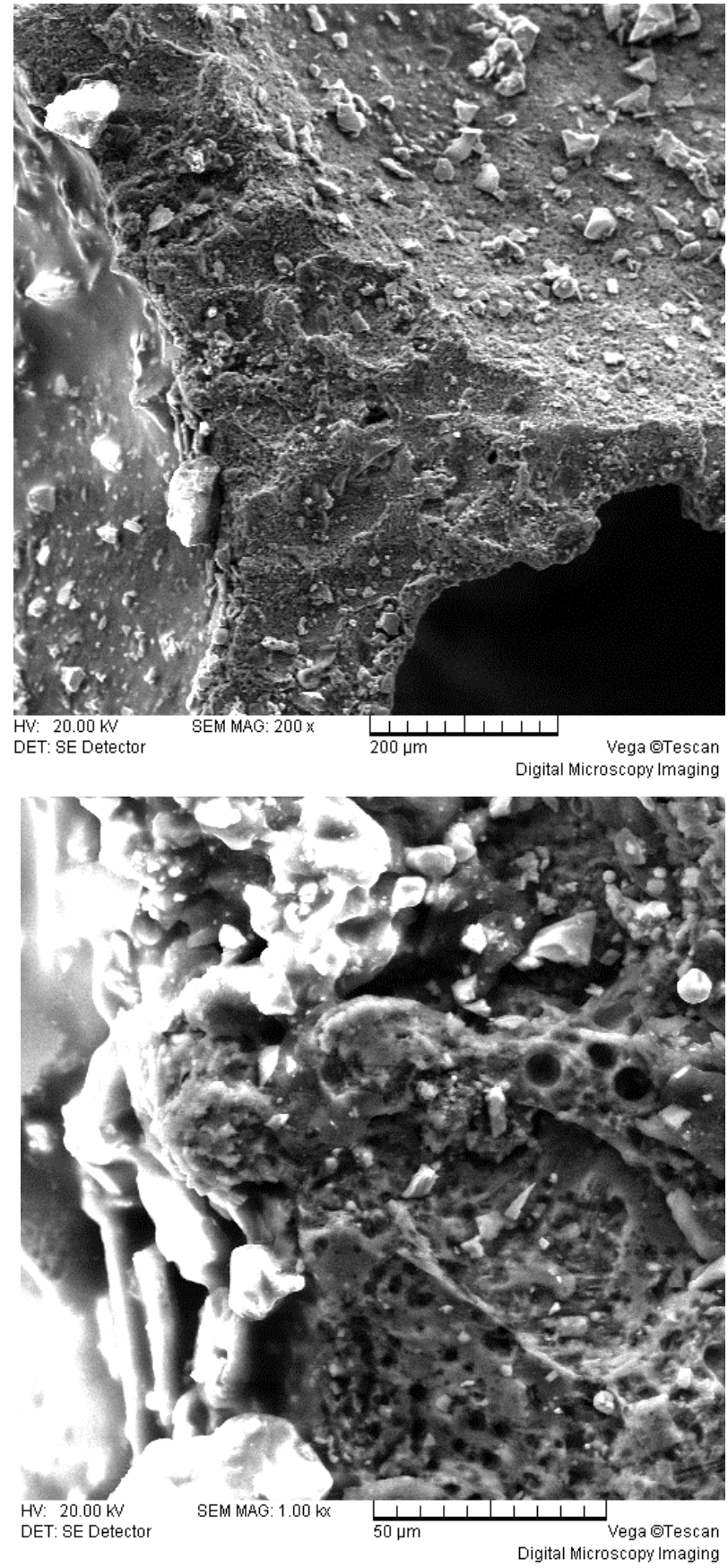

Fig. (12). Microstructure of closed-cell aluminum foam cut by WEDM-HS.

As shown in Figs. (11 and 12), very small smash has been observed on closed-cell aluminum foam surface cut by AWJ, but not on the surface cut by WEDM-HS, which shows that higher cutting force is presented in AWJ cutting process. However, the deformation is small enough to be ignorable in regular applications.

\section{MANUFACTURING EFFICIENCY COMPARISON BETWEEN WEDM-HS AND AWJ}

For any cutting process, time consumed is a very important factor which affects manufacturing cost and cutting efficiency. In order to compare EDM-HS and AWJ cutting processes, time consumed for cutting specially designed sample has been recorded. For WEDM-HS, the whole cutting process lasted hours. Since the machining process is not a continuous process, in order to record the consumed time accurately, the cutting process has been split into 15 items according to each item's feature, as shown in Fig. (6), and the cutting time consumed for each item has been recorded and total consumed time has been calculated, as shown in Table $\mathbf{5}$.

Note: in Table 5, I represents item. For each item, no matter whether it is a square feature or a hole, drilling process is needed before each feature is cut by WEDM-HS. The drilling process is carried out on a regular drilling machine, and an average period of drilling time, 5 minutes each, has been used as drilling time. Also, wire feeding process is needed for each feature. In this cutting process, another average period of time for wire feeding, 2 minutes each, has been used. With considering feature drilling time, wire feeding time and actual cutting time, total cutting time for each feature has been listed in Table 5. For AWJ, however, the total cutting time lasted only minutes, and the whole cutting process is a continuous process. Only total consumed time has been recorded. In this test, two samples have been cut by OMAX2626/XP waterjet machining system. One is cut with quality 3 cutting speed, and another is cut with quality 5 cutting speed. And the total cutting time for each sample is recorded in Table 6.

Table 6. Time Consumed for each AWJ Sample

\begin{tabular}{|c|c|c|}
\hline Sample & Sample \#1 (quality 5) & Sample \#2 (quality 3) \\
\hline Consumed time (min) & 5.55 & 4.83 \\
\hline
\end{tabular}

As shown in Tables 5 and $\mathbf{6}$, to achieve the same profile, more than two and half hours has been consumed by using WEDM-HS machine. Instead, if the sample is cut by AWJ, around 5 minutes is needed.

\section{DISCUSSIONS AND CONCLUSIONS}

As two popular non-traditional machining methods, WEDM-HS and AWJ share some common features as listed in following: (1). Both of them have advantages on machining difficult-to-machine materials; (2). Both of them are used extensively in plate cutting; (3). Both of them are non-contacting machining process; (4). Both of them are with very low cutting force. However, when examining 
closely, several major differences exist between these two processes. Those major differences can be summarized as following: (1). Micro-melting is the working mechanism for WEDM-HS, but for AWJ, micro-cutting is the major working mechanism for ductile material; (2). Similar cutting precision and surface roughness can be achieved; (3). Surface damage can not be avoided completely during machining process, no matter the surface is machined by WEDM-HS or by AWJ. However, for WEDM-HS, the damage mainly comes from much heat generated in cutting zone during cutting process, and for AWJ, the damage mainly comes from deformation caused by cutting force. Need to note that, cutting force generated from AWJ process is small enough to be ignored for usual applications. Even for closed-cell aluminum foam whose wall is very thin and weak, and a very small cutting force would deform it, but after cut with AWJ, the deformation is small enough to be ignored. (4). To cut the same profile, much less time is used when it is cut by AWJ, which shows that AWJ is a very efficient process comparing with WEDM-HS.

\section{ACKNOWLEDGEMENTS}

This research was supported by the National Innovate Research Groups Foundation of China (50621403), Natural Science Foundation Project of CQ CSTC (2009BB4038) and Fundamental Research Funds for the Central Universities (CDJRC 10240007).

\section{REFERENCES}

[1] Wikipedia. "Electrical discharge machining". [Online]. Available from: http://en.wikipedia.org/wiki/Electrical_discharge_machining [Accessed: 12th Sept. 2010].

[2] P. Fallböhmer, T. Altan, H. -K. Tönshoff, and T. Nakagawa, "Survey of the die and mold manufacturing industry - practices in Germany, Japan, and the United States", Journal of Materials Processing Technology, vol. 59, no. 1-2, pp. 158-168, May 1996.

[3] G. Xiong, M. Zheng, D. Li, L. Zhao, Y. Wang, and M. Li, "Study on the influence of non-electrical parameters on processing quality of WEDM-HS and improvement measures", Computer and Computing Technology in Agriculture IV, IFIP Advances in
Information and Communication Technology, vol. 347/2011, pp. 514-520, 2011.

[4] G. Xiong, J. Zhang, L. Zhao, M. Li, "The methods to implement multi-cutting of WEDM-HS", in International Conference on Mechanic Automation and Control Engineering, MACE2010, pp. 3180-3182, June 2010.

[5] J. Yuan, K. Wang, T. Yu, M. Fang, "Reliable multi-objective optimization of high-speed WEDM process based on Gaussian process regression", International Journal of Machine Tools and Manufacture, vol. 48, no. 1, pp. 47-60, January 2008.

[6] Zhongyi X. "Design and development of the control system of the HS-WEDM", thesis, Zhejiang University of Technology, Zhejiang, China, 2009.

[7] A. Chillman, M. Ramulu, "Observations of titanium surfaces impinged with ultra-high pressure waterjets", American WJTA Conference and Expo, pp. 18-20, Houston, Texas, 2009.

[8] J. Zeng, "Erosion of brittle materials in AWJ processing", Dissertation, University of Rhode Island, Rhode Island, America, 1992.

[9] S. Zhang, X. Li, and Y. Gu, "Air flow exploration of abrasive feed tube", Acta Mechani ca Sinica, vol. 25, no. 6, pp. 400-408, 2009.

[10] Koelsch, J. R., "Waterjet vs. EDM", Manufacturing Engineering, vol.135, no. 4, Oct. 2005.

[11] Y. Otsuka, Y. Nakai, M. Numano, T. Maruyama, N. Ohkubo, H. Kishida, "Development of high-speed electrode wire for wire electro-discharge machining", SEI Technical Review, no. 51, pp. 133-136, Jan 2001.

[12] T. Wang, X.C. Lu, F. Qiu, "Design and simulation for multi-axis HS-WEDM system", Applied Mechanics and Materials, vol.16-19, pp. 1387-1391, 2009.

[13] T. Wang, Y.M. Lu, S.S. Hao, S.Q. Xie, X.C. Xu, Y. Wang, "Dry WEDM in improving HS-WEDMed surface quality", Key Engineering Materials, vol. 392-394, pp. 624-628, 2009.

[14] Wire Cut Company. "EDM Drilling-Small Hole EDM Micro Hole Drilling-Conventional \& Wire EDM". [Online]. Available from: http://wirecut-co.com/capabilities.asp [Accessed: 18th Sept. 2010].

[15] Wwwiefly. "Wire cut-high speed, medium speed and low speed". [Online]. Available from: http://blog.sina.com.cn/s/blog 4dbd2f740100fywn.html [Accessed: 16th Sept. 2010].

[16] S. Zhang, D. Chen, Y. Wu, "Hole-drilling using an abrasive water jet in titanium", International Journal of Machining and Machinability of Materials, vol. 9, no. 1, pp. 47-65, 2009.

[17] S. Zhang, X. Li, "Theoretical analysis of piercing delicate materials with abrasive waterjet", Journal of the Chinese Institute of Engineering, vol. 33, no. 7, pp. 5-13, 2010.

[18] S. Zhang, X. Li, Y. Gu, "Optimum abrasive flow rate modeling for titanium alloy cutting using abrasive water jet", International Journal of Abrasive Technology, vol. 2, no. 4, pp. 400-419, 2009. 